\title{
Immunosensors Based on Interdigitated Electrodes for the Detection and Quantification of Pesticides in Food
}

\author{
E. Valera ${ }^{1,2}$ and A Rodríguez ${ }^{3}$ \\ ${ }^{1}$ Applied Molecular Receptors Group (AMRg), IQAC-CSIC, Barcelona, \\ ${ }^{2}$ CIBER de Bioingeniería, Biomateriales y Nanomedicina (CIBER-BBN), Barcelona, \\ ${ }^{3}$ Micro and Nano Technologies Group (MNTg), Departament d'Enginyeria Electrònica, \\ Universitat Politècnica de Catalunya, C/., Barcelona, \\ Spain
}

\section{Introduction}

The use of substances addressed to prevent, destroy or control pests has helped to protect mankind against many different types of pests. Pesticides have been used since ancient times but the discovery of new chemicals boosted their use in the second half of the $20^{\text {th }}$ century. Pesticides used in agriculture made possible to hugely increase and improve production, helping to control insects, bacteria, fungi, herbs, etc. The benefits of their use and their impact in the economy were great and, therefore, the use of pesticides spread rapidly all around the world. The intensive use of pesticides raised concerns about their possible negative effects. Thus, extensive research has been carried out on the effect of pesticides on health, environmental pollution and impact on wildlife. This fact has leaded to the development of new international and national regulations for the rational use of pesticides.

In relation to health, pesticides can penetrate into human bodies in different ways: they can be inhaled by breathing, they can enter through the skin or wounds, and obviously they can be ingested by eating foods containing residual amounts of pesticides. Pesticides are not necessarily poisonous but they may be toxic. The effect of each pesticide on human health depends on the dose and time of contact. Regulations specify maximum residue levels, highest concentration of each pesticide that is allowed to be present in foods. Thus, the European Community has established maximum residue levels for the different pesticides (Council Directives 76/895/EEC, 86/362/EEC, 86/363/EEC and 90/642/EEC) and particularly for atrazine (Directive $93 / 58 /$ EEC), in various foodstuff products.

Many types of sensors have been developed for the detection and quantification of pesticides and traces of them. The MRL of a given pesticide, which often lies in the order of few tens of ppbs, determines the minimum sensitivity of these sensors. Also the quantification, or the detection, of one substance in the complex chemical matrix of some foods as wine, milk or juices also poses important requirements to their selectivity. Traditionally, samples of the products to be analyzed were taken to laboratories where 
precise apparatus based on chromatography methods such as HPLC or GC/MS are able to perform the analysis. These processes of analysis involving the transport to the samples, the analysis and the communication of results, can be time consuming and may be expensive.

It is of high interest to analyze food products at different points of the food chain: recollection, transport, storage, consumption, etc. In particular, with foods like wine, milk, juices, etc, producers take their products to common collection points, where they are mixed with products of other producers. Analysis should be done at this point in order to reject contaminated products before mixing them with good ones.

In order to be able to fabricate these sensors, several conditions need to be accomplished: (i) to maintain the required selectivity and sensitivity, (ii) sensors need to be fast and (iii) the price of each analysis has to be acceptable. Besides, it would be interesting that the sensing system could be portable or at least, compact, and also that the process of analysis would not require specialized personnel, providing a result of simple interpretation with a minimum of sample manipulation. The previous statements are based on a careful market study of the wine industry performed during the initial stage of the European Project GoodFood (FP6-IST-1-508744-IP).

The two types of immunosensors studied in this chapter have been oriented towards the detection of small amount of pesticides residues in wine samples. They are based on the use of: i) interdigitated $\mu$-electrodes (ID $\mu E^{\prime} s$ ) arrays; and ii) bioreagents specifically developed (antigen, antibody).

The main characterization method used in the study of these immunosensors has been impedance spectroscopy in a wide range of frequencies $(40 \mathrm{~Hz}-1 \mathrm{MHz})$. Nevertheless, besides impedance spectroscopy, the immunosensors developed have been also characterized by means of other impedance methods as well as chemical affinity methods in order to contrast their performances. The immunosensors developed have been named:

i. Impedimetric immunosensor;

ii. Conductimetric immunosensor.

The nomenclature used is related to the detection methods applied in the present work. In the case of the impedimetric immunosensor the detection method is based on impedimetric measurements (in a wide range of frequencies), whereas in the case of the conductimetric immunosensor, the detection method is based on conductimetric measurements (DC measurements). For the case of the conductimetric immunosensor, conductimetric measurements as detection method are possible because this sensor is labelled with gold nanoparticles.

\section{Description of the immunosensors}

In this section, the basic ideas underlying the structure, functionalization and working mechanisms of the biosensors treated in this chapter are described.

\subsection{Interdigitated $\mu$-electrodes (ID $\mu \mathrm{E}$ 's)}

As it has been commented before, interdigitated $\mu$-electrodes (ID $\left.\mu E^{\prime} s\right)$ were used as transducers for the immunosensors presented in this chapter. Interdigitated $\mu$-electrodes are 
two coplanar electrodes (that works as counter and working electrodes) which have equal surface areas and each is presumed to contribute equally to the measured network impedance. The procedure of the electrodes fabrication is as follows:

Thin $\mathrm{Au} / \mathrm{Cr}$ ( $200 \mathrm{~nm}$ thickness) interdigitated $\mu$-electrodes (ID $\left.\mu E^{\prime} \mathrm{s}\right)$ with, $3.85 \mu \mathrm{m}$ thick with electrode gap of $6.8 \mu \mathrm{m}$ were patterned on a Pyrex 7740 glass substrate (purchased from Pröazisions Glas \& Optik $\mathrm{GmbH}, 0.7 \mathrm{~mm}( \pm 0.05)$ thickness). The chromium layer is much thinner than the gold layer and it is deposited prior to gold just to improve the adhesion of the gold to the Pyrex substrate. Before metal deposition, the Pyrex substrate was cleaned using absolute ethanol. The metal deposition was performed by means of sputtering deposition and the interdigitated $\mu$-electrodes were then patterned on the Pyrex substrate by a photolithographic metal etch process. For the immunosensor measurements, arrays consisting on six ID $\mu E^{\prime}$ s organized on a $0.99 \mathrm{~cm}^{2}$ area were constructed.

Before functionalization, the samples were first cleaned in a solution of ethanol absolute $70 \%$ and Milli-Q water $30 \%$. Then, the samples were plunged for $12 \mathrm{~h}$ in a solution of $\mathrm{NaOH}$ $2.5 \%$ in Milli-Q water. Afterwards, the $12 \mathrm{~h}$ the samples were rinsed in $100 \mathrm{~mL}$ of Milli-Q water in order to neutralize the action of the $\mathrm{NaOH}$.

Finally, the arrays of ID $\mu E^{\prime}$ s were dried with ethanol and $\mathrm{N}_{2}$.

\subsection{Impedimetric immunosensor}

The impedimetric immunosensor is a robust and label-free device based on the use ID $\mu E^{\prime} s$ arrays, bioreagents specifically developed and on the impedimetric change that occurs when the immunoassay is performed on the electrodes surface.

The assay of detection relies on the immunochemical competitive reaction between the pesticide residues and the immobilized antigen on ID $\mu \mathrm{E}^{\prime} s$ for a small amount of the specific antibody. The detection of a small number of molecules of pesticide residues is performed under competitive conditions involving the competition between the free pesticide (analyte) and a fixed amount of coated antigen for a limited amount (low concentration) of antibody $(\mathrm{Ab})$. At the end of the reaction, the amount of Ab captured on the ID $\mu \mathrm{E}$ surface and hence the free antigen (analyte), is determined.

This competitive assay is fundamental in the immunosensor concept, because, as it can be clearly seen in Figure 1, the immunosensor actually does not measure an amount of pesticide; instead it measures an amount of antibody (related to the target pesticide). Thus, the change in the impedance is due to the addition of antibody in the sensor surface, and not to the addition of molecules of pesticides. This approach has an important effect on the sensitivity of these immunosensors, because the molecules of antibody are much bigger than the molecules of pesticide and their effect on the impedance of the device is much higher. This feature represents an important advantage in comparison with other impedimetric immunosensors reported previously [1-3]. As a consequence, authors of these works must reduce the electrode size to nanometer scale [1], or otherwise their limits of detection can only achieve tens of ppbs [2,3].

Immunosensor functionalization consists on two main steps: i) the coating antigen (CA) immobilization; and ii) the specific antibody capture. These steps will be schematically shown below. The addition of pesticide in residual concentrations, during the antibody 
capture step, makes that a fraction of initial antibodies will be evacuated from the device (Figure 1). Thus, the change in the antibody concentration is equivalent to the pesticide concentration used.

As it is shown herein below, this immunosensor is sensitive to the chemical changes produced at the surface of its interdigitated $\mu$-electrodes, and hence the impedance measured will change following the changes of: (i) the concentration of the immobilized antigen, (ii) the amount of the captured antibody and (iii) the competitive equilibrium between analyte, specific antibody and the competitor antigen.

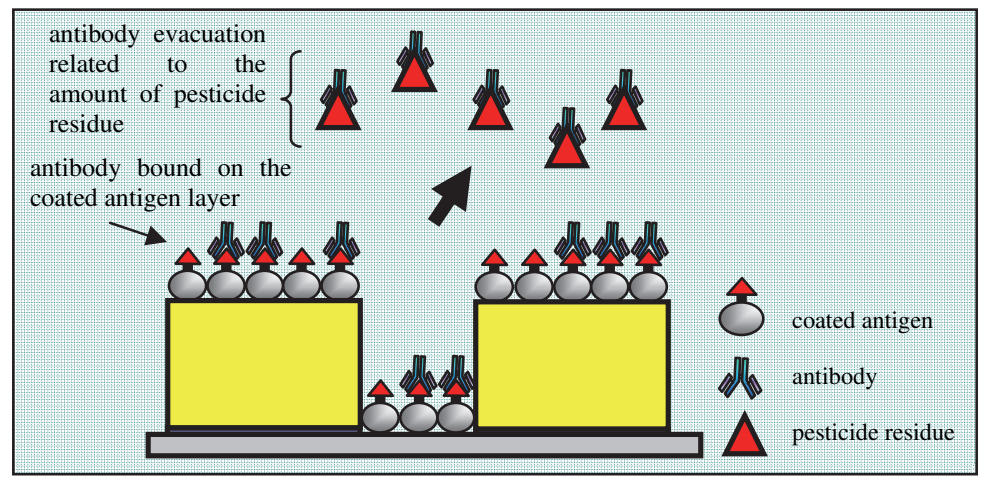

Fig. 1. Immunosensor reaction. An amount of the specific antibody is bound on the coated antigen layer. Other quantity is evacuated of the ID $\mu E^{\prime}$ s; this amount is related to the pesticide concentration.

\subsection{Conductimetric immunosensor}

The conductimetric immunosensor is a labelled device. This device is also based on the use ID $\mu E^{\prime}$ s arrays, bioreagents specifically developed but, in addition, it includes a secondary antibodies labelled with gold nanoparticles. In consequence, in this case the detection principle is based on a conductimetric change which occurs when the secondary antibody is deposited on the electrodes surface, after the immunoassay.

As in the previous case, the assay of detection also relies on the immunochemical competitive reaction between the pesticide residues and the immobilized antigen on ID $\mu \mathrm{E}^{\prime} \mathrm{s}$ for a small amount of the specific antibody. However in this case, a secondary antibody $\left(\mathrm{Ab}_{2}\right)$ is included (Figure 2). These secondary antibodies, linked to the gold particles, constitute a conductive film between the electrodes. Thus, the conductance of this film will depend on the concentration of gold labelled antibodies.

The functionalization of this immunosensor consists in three main steps: i) the coating antigen (CA) immobilization; ii) the specific antibody capture ( $\left(\mathrm{Ab}_{1}\right)$; and iii) the capture of a non- specific antibody $\left(\mathrm{Ab}_{2}\right)$ labelled with gold nanoparticles.

The detection of free pesticide still depends on the competition between the analyte and a fixed amount of CA for a low concentration of $A b_{1}$. After that, $A b_{2}$ is included and linked to $A b_{1}$, then the $A b_{2}$ concentration (and, as a consequence, the amount of gold particles) is related to the $A b_{1}$ concentration included. Therefore, the concentration of the free pesticide 
tested is related to the amount of gold nanoparticles. Again, the immunosensor does not measure directly the quantity of pesticide; in this case an amount of gold particles related to the amount of pesticide, is measured. This procedure is schematically shown in Figure 3.

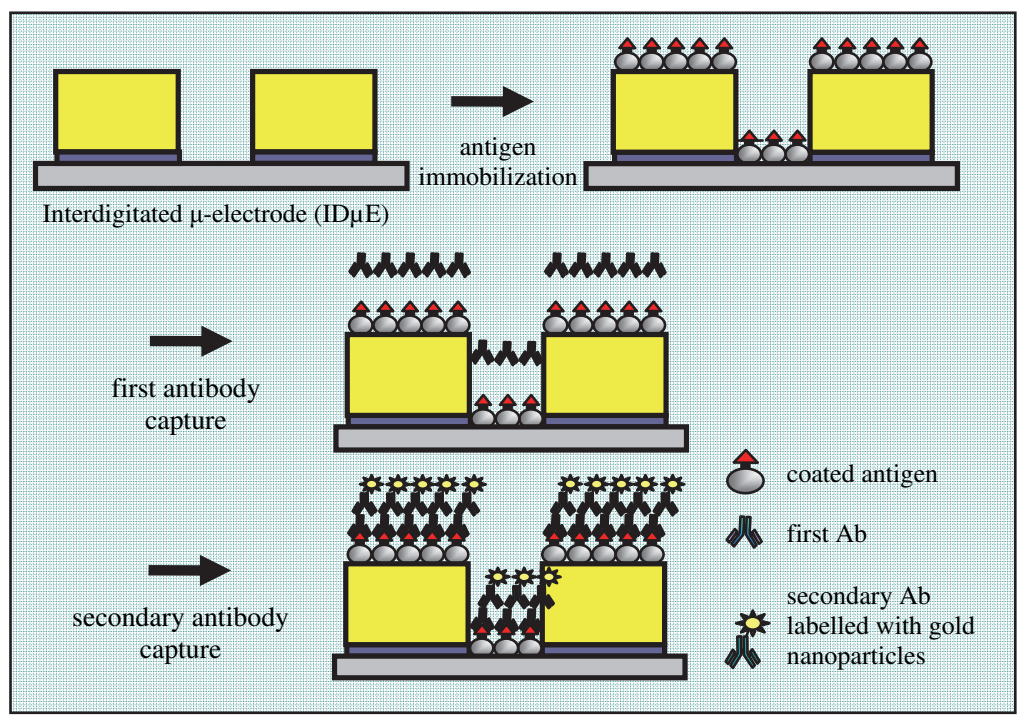

Fig. 2. Schematic diagram of the complete assay system performed on the ID $\mu E^{\prime} s$ for the conductimetric immunosensor.

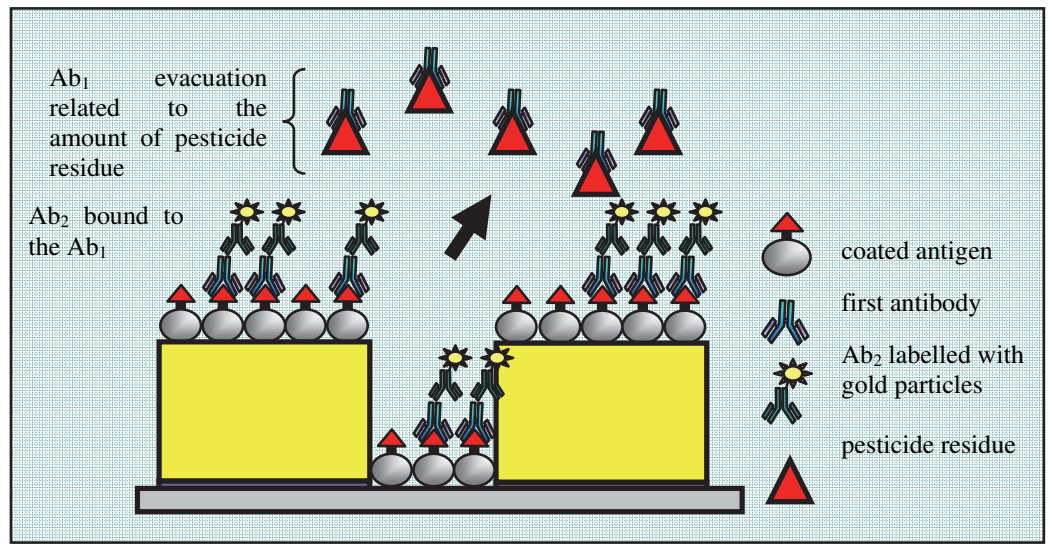

Fig. 3. Immunosensor reaction. An amount of the secondary antibody $\left(\mathrm{Ab}_{2}\right)$ is bound to the specific antibody $\left(A b_{1}\right)$. Previously, an amount of $A b_{1}$ (related to the pesticide residue concentration) was evacuated of the ID $\mu \mathrm{E}^{\prime}$ s; the amount of gold nanoparticles is related to the pesticide residue concentration.

Comparing the functionalization procedures of both immunosensors, apparently the only difference is the inclusion of the gold nanoparticles. However, the consequence of this difference is not only related to the detection method. It is related to the fact that the 
inclusion of the gold nanoparticles causes a very different distribution of electric field in comparison to the case of having only the fingers of the interdigitated electrodes. In this new structure, gold particles act as new small fingers, reducing the gap of the interdigitated $\mu$ electrodes [4].

\section{Functionalization of the Immunosensors}

The biofunctionalization (immobilization) of the biological element onto the transducer surface is required for the immunosensors development. In this section, the functionalization of the immunosensors is explained for all the cases proposed.

Sensor solid surfaces are in general solid inorganic materials not suitable for immobilizing biomolecules. Hence, further modification is required to adapt them for the immobilization of biomolecules. In addition, functional sensor surfaces place several demands such as biocompatibility, homogeneity, stability; specificity; and functionality. Thus, a challenge in biosensor development is to construct adequate surfaces as well as to design molecules suitable for site-directed immobilization. Surface architecture depends on the nature of the transducer and on the features of the biomolecule, as well as the type of measurements to be done [5-8]. The surface has to be activated appropriately for further tethering of the proteins with a particular immobilization method. Subsequent layers can be generated in place, textured following specific demands. A key problem is the non-specific attachment of molecules, sometimes present in the matrix where measurements need to be made, to the surface of the sensor. This happens on any kind of surface, but particularly, gold is very well suited to capture non-specifically organic molecules and components from the media. For that, the affinity of the antibodies as well as the adequate functionalization of the surface (electrodes and gap) is very important.

Immunosensors functionalization is based on the capture of antibodies specifically developed. The function of the antibody is the capture of the antigen and to form with it a complex antibody with the aim to exclude intruders. In addition to the antibody, the immunosensor reaction implies the presence of a coated antigen and the analyte.

The dielectric properties of the biological systems are very remarkable. Thanks to this important characteristic, these devices can exhibit a good impedimetric response.

The detection of pesticides in very low concentrations relies in a competitive reaction between the analyte and an immobilized protein (coated antigen) supported analog. Over the coated layer of antigen, the free specific antibody is captured by affinity. In the case of the conductimetric immunosensor, a secondary antibody labelled with a gold nanoparticle is attached to the primary specific antibody in order to amplify the affinity event and obtain a good conductive response.

In the case of both immunosensors described in this chapter, the method of immobilization used is covalent immobilization, and the procedure is explained hereinafter.

\subsection{Functionalization of the impedimetric immunosensor}

In the case of the impedimetric immunosensor, the chemical changes on the sensor surface follow four steps, two previous steps for the surface functionalization and two more for the immunosensor reaction: 
i. Step I, protection of interdigitated $\mu$-electrodes with $\mathrm{N}$-acetylcysteamine;

ii. Step II, immunosensor surface functionalization with GPTS;

iii. Step III, covalent immobilization of the antigen on the ID $\mu \mathrm{E}$;

iv. Step IV, specific primary antibody $\left(\mathrm{Ab}_{1}\right)$ capture in the competition step;

One of the main consequences of the use of covalent immobilization is that the chemical recognition layer is only deposited on the gap of the interdigitated $\mu$-electrodes, because it is the substrate surface (and not the electrodes) which is functionalizated (Step II). The immunosensor surface functionalization is shown in Figure 4, whereas the complete chemical procedures are schematically described in Figure 5.

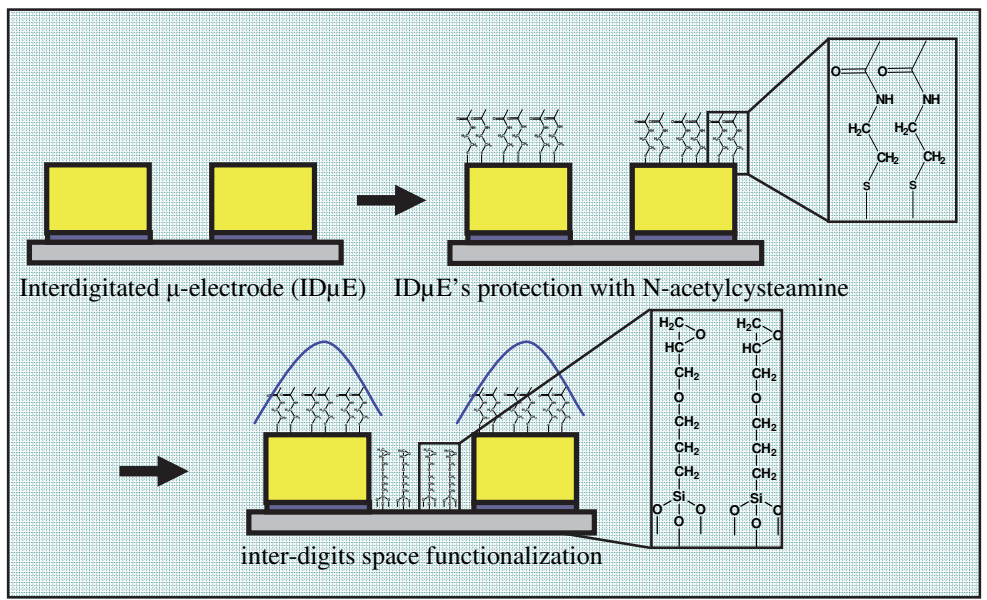

Fig. 4. Schematic diagram of: i) protection of interdigitated $\mu$-electrodes with $\mathrm{N}$ acetylcysteamine; and ii) immunosensor surface functionalization with GPTS.

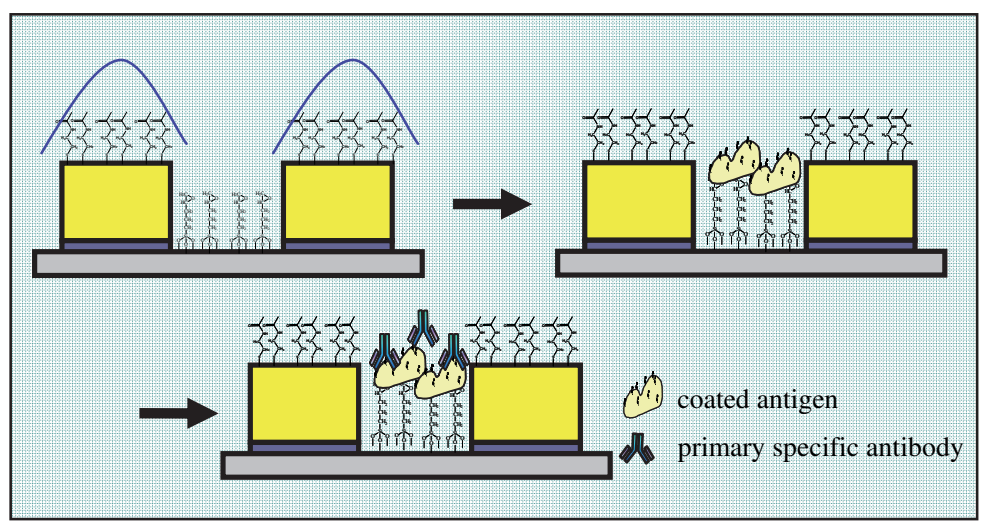

Fig. 5. Schematic diagram of the complete assay system performed on the ID $\mu E^{\prime} s$ for the impedimetric immunosensor.

Activation of gold surfaces is readily and specifically performed using thiol-chemistry. Nacetylcysteamine is used to cover the gold electrodes and to protect the sensor from 
undesired non-specific absorptions (Step I). The resulting Au-S bond grants good stability of the deposited surface layer. In this case, the surface texture of the ID $\mu \mathrm{E}$ defines the template for deposition of layers, since the gold fingers have been deposited on a solid support such as glass with the necessary controlled geometry. This is not the case for glass material that serves as support. Silane-chemistry is the most used activation procedure to functionalize the surface for subsequent covalent coupling of the biomolecules. Thus, in a next step (Step II) the PYREX substrate is derivatized with 3-glycidoxypropyl trimethoxysilane (GPTS). The epoxy group provides the necessary reactivity for further attachment of the bioreagents through a nuchelophylic attack of functional groups of the biomolecule such as the amino groups of the lysine residues. As it has been reported [9], the concentration of the silane ( $2.5 \%$ in anhydrous ethanol) and the reaction time $(12 \mathrm{~h})$ are important for the formation of a homogenous and molecularly smooth epoxysilane layer on the PYREX substrate. Finally, covalent immobilization of the pesticide antigen 2d-BSA is performed on the surface of the interdigitated $\mu$-electrodes via the amino groups of the lysine residues by reaction with the epoxy groups of the surface (Step III).

The impedance of the microelectrodes after the functionalization steps previous to the Step IV will constitute a reference value, and in what follows will be denoted as blank. Blank implies the substrate impedance $\left(Z_{\text {board }}\right)$; the ohmic resistance of the electrolyte (Rs); the contribution to the impedance of the $\mathrm{N}$-acetylcysteamine $\left(Z_{N}\right)$; the contribution of the GPTS ( $\left.Z_{\mathrm{GPTS}}\right)$; and the impedance of the antigen $\left(Z_{\mathrm{AT}}\right)$. Therefore, the impedance of interest is the increment of impedance between Step III and Step IV $\left(Z_{\mathrm{Ab}}-\left[Z_{N}+Z_{\mathrm{GPTS}}+\mathrm{Z}_{\mathrm{AT}}\right]\right)$.

\subsection{Functionalization of the conductimetric immunosensor}

As in the case of the impedimetric immunosensor, a covalent immobilization technique was also applied to the conductimetric immunosensor. The chemical changes on the conductimetric immunosensor surface follow five steps, two previous steps for the immunosensor surface functionalization and other three steps for the immunosensor reaction:

i. Step I, protection of interdigitated $\mu$-electrodes with $\mathrm{N}$-acetylcysteamine;

ii. Step II, immunosensor surface functionalization with GPTS;

iii. Step III, covalent immobilization of the antigen on the ID $\mu \mathrm{E}$;

iv. Step IV, specific primary antibody $\left(\mathrm{Ab}_{1}\right)$ capture in the competition step;

v. Step $\mathrm{V}$, secondary labelled with gold antibody $\left(\mathrm{Ab}_{2}\right)$ capture.

As in the case of the impedimetric immunosensor, the chemical recognition layer was deposited only on the gap of the interdigitated $\mu$-electrodes. The immunosensor surface functionalization was the same applied to the impedimetric immunosensor (Figure 4). The complete functionalization procedures of the conductimetric immunosensor are schematically shown in Figure 6.

As in the case of the impedimetric immunosensor, the blank was also defined. In this case, blank is the contribution in impedance related to the functionalization steps previous to the Step V. Thus, blank implies the substrate impedance $\left(Z_{\text {board }}\right)$; the ohmic resistance of the electrolyte (Rs); the contribution to the impedance of the $\mathrm{N}$-acetylcysteamine $\left(\mathrm{Z}_{\mathrm{N}}\right)$; the contribution of the GPTS $\left(Z_{\mathrm{GPTS}}\right)$; the impedance of the antigen $\left(\mathrm{Z}_{\mathrm{AT}}\right)$; and the impedance of 
the primary antibody $\left(Z_{\mathrm{Ab1}}\right)$. Therefore, the impedance of interest is the delta (variation) of impedance between Step IV and Step V ([Z $\left.\left.Z_{\mathrm{Ab} 2+\text { gold particles }}\right]-\left[Z_{\mathrm{Ab}}+Z_{\mathrm{N}}+Z_{\mathrm{GPTS}}+\mathrm{Z}_{\mathrm{AT}}\right]\right)$.

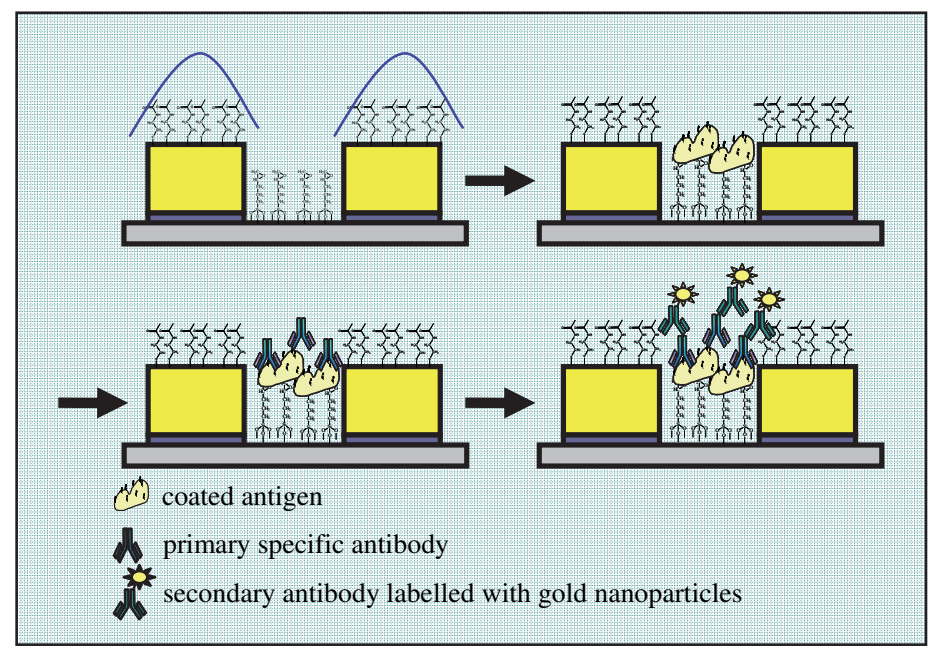

Fig. 6. Schematic diagram of the complete assay system performed on the ID $\mu E^{\prime}$ s for the conductimetric immunosensor.

\section{Pesticide residues detection in buffer samples}

Both types of immunosensors described in previous sections (impedimetric and conductimetric) have been tested for the detection of free pesticide in buffer samples. For that, atrazine, a widely used pesticide in the wine industry, as well as for the test of novel biosensors [10-14], has been used as pesticide of test.

Atrazine and related triazines such as ametryn, propazine, prometryn, prometon, simazine and terbutryn, are widely used selective herbicides for the control of annual grasses and broadleaved weeds. Therefore, herbicide residues can contaminate crops, wells, and streams due to spills, spraying and run-off. They have often been found in drinking water, and therefore, they are a potential threat for the public health [15-18]. The European Community has established maximum residue level for residues of this herbicide in wine grapes in $50 \mu \mathrm{g} \mathrm{L}-1$.

The competitive reaction carried out on the interdigitated $\mu$-electrodes has been performed in buffer solution (assay buffer). The performance details of both types of devices as atrazine detectors are detailed below.

\subsection{Impedimetric immunosensor}

\subsubsection{Detection method applied: Impedance spectroscopy}

One of the quantitative tools adequate to provide sensitivity graphs is the impedance characterization measurement in a wide frequency range and the fitting of the Nyquist plots of impedance spectra to an equivalent circuit. The use of this technique and Nyquist plots 
are a very common strategy in the literature for the biosensors characterization [2, 3, 19-23]. By this technique, the concentration of free pesticide should finally be related to the values of at least some of the parameters of the equivalent circuit.

The equivalent circuit used is shown in Figure 7. The circuit is an equivalent electrical circuit that consists of:

i. contact resistance, Rc;

ii. capacitance of the ID $\mu \mathrm{E}, \mathrm{C}_{\mathrm{ID} \mu \mathrm{E}}$;

iii. the Warburg impedance, $\mathrm{Zw}$;

iv. the double layer capacitance, $\mathrm{Cdl}$; and

v. Polarization resistance; Rp.

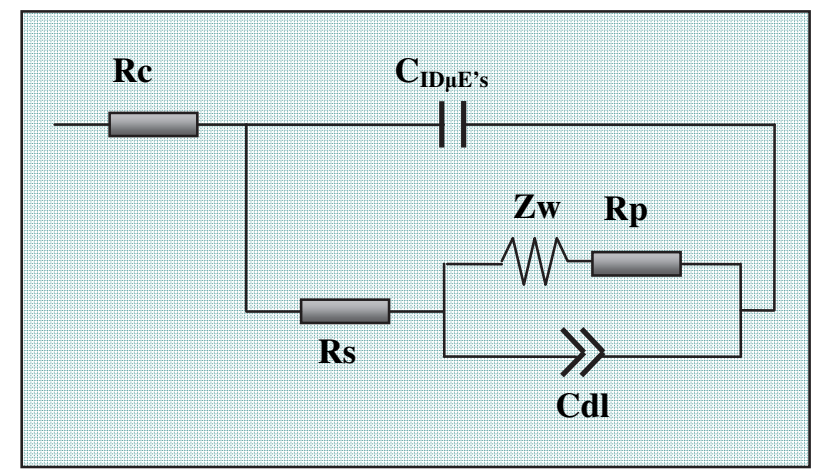

Fig. 7. Simplified version of the equivalent circuit of the implemented system.

Impedance spectroscopy requires a wide bandwidth of work, the application of a periodic small amplitude AC signal, as well as a solution as medium (typically a buffer) for charge transport. For the impedimetric immunosensor characterization, frequencies in the range of $40 \mathrm{~Hz}-1 \mathrm{MHz}$; 0V of polarization potential; a modulation voltage of $25 \mathrm{mV}$ amplitude; and a phosphate buffer solution (PBS @ $1.6 \mu \mathrm{S} \mathrm{cm}^{-1}$ ) as medium were used.

After performing the measurements, response curves are fitted to the following fourparameter equation [24]:

$$
Y=\left\{\frac{A-B}{1+(x / C)^{D}}\right\}+B
$$

where $\mathrm{A}$ is the absolute maximal signal (zero analyte concentration), $\mathrm{B}$ is the absolute minimum signal (infinite analyte concentration), $\mathrm{C}$ is the concentration producing $50 \%$ of the maximal signal change, and D is the slope at the inflection point of the sigmoid curve.

As an example, the Nyquist plots of impedance spectra of layer-by-layer, under covalent immobilization conditions, are shown in Figure 8. As it can be seen, an excellent fitting between the simulated and experimental spectra has been obtained for all the curves. Curve $8 \mathrm{a}$ is the impedance spectrum after $1 \mu \mathrm{g} \mathrm{mL}^{-1}$ concentration of antigen immobilization, while the curve $8 \mathrm{~b}$ is the impedance spectrum after the specific antibody capture in $1 \mu \mathrm{g} \mathrm{mL}^{-1}$ concentration. 


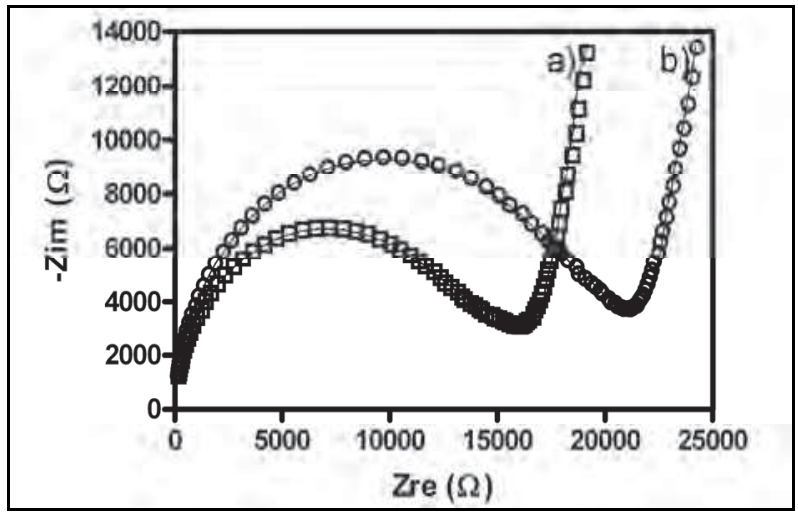

Fig. 8. Nyquist plot of impedance spectra corresponding to: a) Step III: covalent immobilization of the antigen on the ID $\mu \mathrm{E}$, and b) Step IV: specific antibody $(\mathrm{Ab})$ capture in the competition step, taken in diluted PBS solution without redox couple. Symbols represent the experimental data. Solid curves represent the computer fitting data with the parameters calculated by a commercially available software Zplot/Zview (Scibner Associates Inc.) using the equivalent circuit shown in Figure 7.

\subsubsection{Atrazine detection in buffer samples}

In order to detect atrazine in buffer samples using the impedimetric immunosensor, buffer samples were doped with different atrazine concentracion in the range of $0.32-2000 \mu \mathrm{g} \mathrm{L}-1$. The experiments were conducted including these concentrations of atrazine during the competition step using different ID's samples for every concentration. The response curve obtained, using the tool of detection in a range of frequencies, the covalent immobilization technique, as well as assay buffer, can be seen in Figure 9.

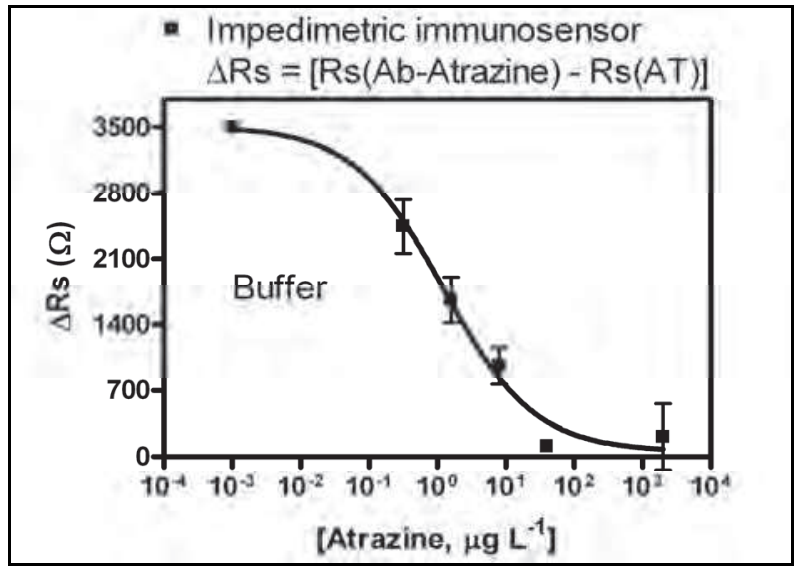

Fig. 9. Response curve of the impedimetric immunosensor, using the covalent immobilization technique, for the atrazine detection in relation with the Rs variation. Buffer solution was used for the competitive reaction. Measures were taken in diluted PBS solution. See Table 1 for the features of the atrazine assay. 
All measurements were differential in order to suppress the non-ideal effects related to the geometry or technology of the ID $\mu E^{\prime}$ s. Likewise, the variation of Rs in relation with atrazine concentration was selected and analyzed from the computer fitting data. In all cases, the change in the value of Rs (denoted $\Delta$ Rs in Figure 9) was taken between the Step III and Step IV of the impedimetric immunosensor functionalization. Due to the competitive assay performed, $\Delta$ Rs decreases as the concentration of atrazine increases.

The limit of detection obtained from the response curve shown in Figure 9 was $\mathbf{0 . 0 4} \mu \mathbf{g} \mathbf{L}^{-\mathbf{1}}$. This value is not only far below the MRL required by EC, but it also shows a huge improvement on the results obtained when the passive adsorption was applied.

\begin{tabular}{ll}
\hline $\begin{array}{l}\text { Features of the atrazine } \\
\text { assay }\end{array}$ & $\begin{array}{l}\text { Impedimetric immunosensor } \\
\text { (Buffer) }\end{array}$ \\
\hline Signal $_{\min }$ & $56.3^{\mathrm{b}}$ \\
\hline Signal $_{\max }$ & $3510^{\mathrm{b}}$ \\
\hline Slope & -0.66 \\
\hline $\mathrm{IC}_{50, \mu \mathrm{g} \mathrm{L}^{-1}}$ & 1.23 \\
\hline $\mathrm{LOD}, \mu \mathrm{g} \mathrm{L}^{-1}$ & $\mathbf{0 . 0 4}$ \\
\hline $\mathrm{R} 2$ & 0.91 \\
\hline
\end{tabular}

a The parameters are extracted from the four-parameter equation used to fit the standard curve.

b Values presented are in $\Omega$.

Table 1. Features of the atrazine assaysa.

\subsection{Conductimetric immunosensor}

\subsubsection{Detection method applied: DC measurements}

Although a priori DC measurements do not seem a great contribution as detection method, they represent a very important approach of the conductimetric immunosensor, because these DC measurements are based on the gold nanoparticles attached to the immunosensor. With this method, it was proven that pesticides in residual amounts can be detected by means of simple and inexpensive DC measurements provided gold nanoparticles are included as labels in the immunosensor $[25,26]$.

When a DC voltage is applied to an interdigitated $\mu$-electrode without gold nanobeads, the DC current obtained is low because the dielectric properties of the bioreagents and the gap that separates the electrodes. Nevertheless, when the same DC voltage is applied to an interdigitated $\mu$-electrode with gold particles attached to it, the DC current which passed through the electrodes grows clearly. Furthermore, if the concentration of gold particles is in relation to the concentration of pesticide, then the current values obtained will also be.

Thus, the measurement of the conductance (DC current) after the inclusion of the gold nanoparticles on the immunosensor is a quantitative tool adequate to provide sensitivity 
graphs. Then, the concentration of pesticide should finally be related to the amount of gold nanoparticles present on the immunosensor.

On the other hand, detection techniques based on impedimetric measurements were discarded in the case of the conductimetric immunosensor because the inclusion of the gold particles is a handicap for the impedimetric response. An important advantage of the competitive assay used is that the impedimetric variation is related to the molecules of antibody, instead the molecules of pesticide (smaller than the antibody molecules). Therefore, applying impedimetric measurements to the conductimetric immunosensors, this advantage is reduced, because the contribution of the gold particles (conductive elements) subtracts the secondary antibody contribution.

\subsubsection{Atrazine detection in buffer samples}

As in the previous case, experiments were carried out including atrazine concentrations between 0.32 to $2000 \mu \mathrm{g} \mathrm{L} \mathrm{L}^{-1}$ during the competition step (Step IV) and using different ID's arrays for every concentration. The electrodes were covered by a diluted PBS solution and the measurements were executed to +25 and $+100 \mathrm{mVdc}$ bias. DC voltages were chosen under $100 \mathrm{mV}$ bias in order to avoid the electrolysis of water. Likewise, the blank was measured and reduced from the data measured after Step V in order to take into account only the contribution of the gold nanoparticles. The results obtained by this method are represented in Figure 10. Again, the atrazine response of the sensor follows an inverse law and hence the response is larger at low concentrations of atrazine. The limits of detection obtained for the atrazine residues detection using the conductimetric immunosensors, when the competitive assay was performed in buffer solution, were $\mathbf{0 . 4 4 6} \mu \mathrm{g} \mathrm{L}^{-1}$ (100 $\mathrm{mVdc}$ bias) and $1.217 \mu \mathrm{g} \mathrm{L}^{-1}$ (25 mVdc bias), both far below the MRL.

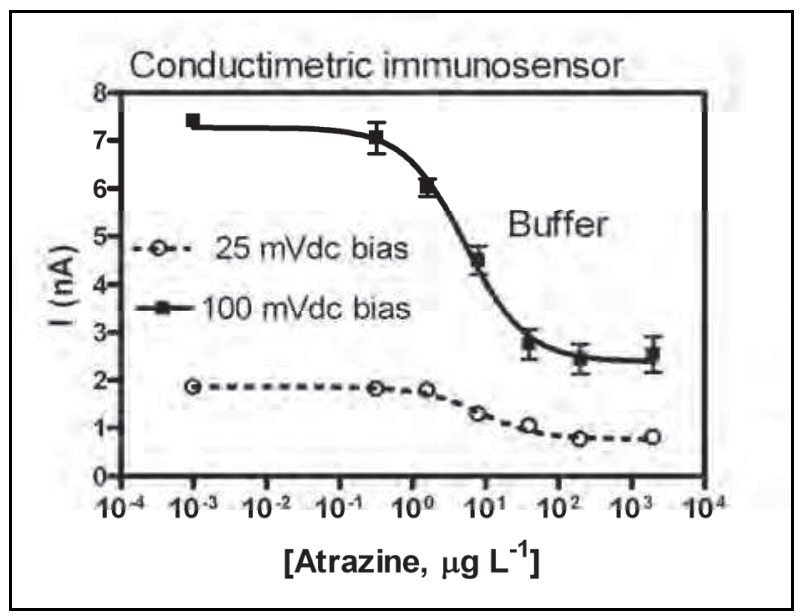

Fig. 10. Response curve of the conductimetric immunosensor, using the covalent immobilization technique, for the atrazine detection in relation with the presence of gold particles $(40 \mathrm{~nm})$. Buffer solution was used for the competitive reaction. Measures were taken in diluted PBS solution and the blank was reduced. See Table 2 for the features of the atrazine assay. 


\begin{tabular}{lll}
\hline \multirow{2}{*}{$\begin{array}{l}\text { Features of the atrazine } \\
\text { assays }\end{array}$} & \multicolumn{2}{l}{$\begin{array}{l}\text { Conductimetric immunosensor } \\
\text { (buffer) }\end{array}$} \\
\cline { 2 - 3 } & $25 \mathrm{mV}$ & $100 \mathrm{mV}$ \\
\hline $\mathrm{IC}_{50}, \mu \mathrm{g} \mathrm{L}^{-1}$ & $8.47 \pm 0.19$ & $5.29 \pm 0.14$ \\
$\mathrm{LOD}, \mu \mathrm{g} \mathrm{L}^{-1}$ & $\mathbf{1 . 2 1 7}$ & $\mathbf{0 . 4 6 6}$ \\
$\mathrm{R}^{2}$ & 0.89 & 0.91 \\
\hline
\end{tabular}

a The parameters are extracted from the four-parameter equation used to fit the standard curve.

Table 2. Features of the atrazine assaysa.

\subsection{New approach: a flexible device}

As it was proven in the previous sections, both types of immunosensors described in this chapter have been able to detect residues of atrazine when buffer samples were used for the competitive assay. In both cases, the transducer was supported by a PYREX substrate.

In this section a new approach is introduced, the possibility of low cost, flexible plastic substrates.

\subsubsection{Flexible interdigitated $\mu$-electrode (FID $\mu \mathrm{E})$}

PYREX properly complies with the conditions of isolation and compatibility necessary, and, furthermore, it gives a great rigidity and stability to the device. Nevertheless, the possibility of a flexible sensor has also been explored. Therefore, the first step to carry out this idea is the development of ID $\mu E^{\prime}$ s with flexible features. Flexible interdigitated $\mu$-electrodes $(\mathrm{FID} \mu \mathrm{E})$ for biosensor applications have also been fabricated. A sample of these FID $\mu \mathrm{E}^{\prime} \mathrm{s}$ can be seen in Figure 11.
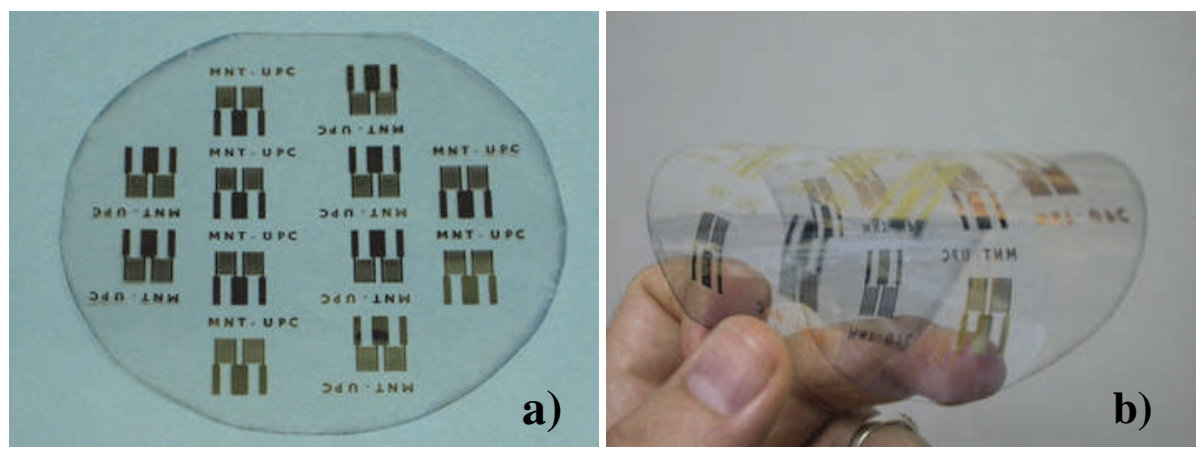

Fig. 11. Flexible interdigitated $\mu$-electrodes fabricated: a) top view; b) demonstration of flexibility.

The flexibility of the FID $\mu E^{\prime}$ s is related to the plastic substrate where the electrodes are deposited. The plastic chosen as new substrate was polyethylene naphthalate (PEN), 0.075 $\mathrm{mm}$, purchased from Goodfellow Cambridge Limited. PEN was chosen instead of other plastics such as Polyethylene terephthalate (PET) or Polycarbonate (PC), because it brings 
together important features that make it compatible with the microelectronic technology such as:

i. chemical resistance: acids - dilute (good), alcohols (good);

ii. electrical properties: dielectric constant @ $1 \mathrm{MHz}(3.2 @ 10 \mathrm{kHz})$, surface resistivity $\left(10^{14}\right.$ $\Omega / \mathrm{sq})$;

iii. thermal properties: upper working temperature $\left(155^{\circ} \mathrm{C}\right)$.

The fabrication procedure of the FID $\mu E^{\prime} s$ is as follows: Thin Au (150 - $200 \mathrm{~nm}$ thickness) interdigitated $\mu$-electrodes (ID $\mu E^{\prime}$ s) with, $30 \mu \mathrm{m}$ thick with electrode gap of $30 \mu \mathrm{m}$ were patterned on a PEN substrate. In this case, the chromium layer is avoided because the good adhesion between gold and the PEN substrate. Before metal deposition, the PEN substrate was cleaned using absolute ethanol. The metal deposition was performed by means of sputtering deposition and the interdigitated $\mu$-electrodes were then patterned on the PEN substrate by a photolithographic metal etch process.

FID $\mu E^{\prime}$ s solves the problem of the flexible electrodes; nevertheless, in order to obtain an immunosensor, the sensor surface must offer good biochemical behaviour. A material as polyethylene naphthalate, used for electronic applications, is not biocompatible. Therefore, the functionalization by means of covalent immobilization techniques could not be performed on PEN. To solve this problem, a biocompatible layer must be deposited, at least, on the gap surface. For this reason, $\mathrm{SiO}_{2}$ was deposited by sputtering on the electrodes surface, because silicon oxide surface contains reactive $\mathrm{SiOH}$ groups, which can be used for covalent attachment of organic molecules and polymers [27].

\subsubsection{Conductimetric immunosensor using FID $\mu E$ 's}

After the deposition of the biocompatible layer $\left(\mathrm{SiO}_{2}\right)$, the conductimetric immunosensor performance was analyzed using the new FID $\mu E^{\prime} s$. The functionalization performed followed the covalent immobilization techniques detailed in previous sections herein above.

Firstly, an analysis of the impedimetric response was developed in order to prove that the new electrodes are able to monitoring the impedance variations related to the presence of the bioreagents. Thus, in order to qualitatively show how the immunosensor is sensitive to the atrazine concentration, experiments in assay buffer were conducted including different values of atrazine concentration $\left(0.32-2000 \mu \mathrm{g} \mathrm{L}^{-1}\right)$ during the competition step using different ID's samples for every concentration. Although, as it has been previously mentioned impedimetric detection is not recommended for the conductimetric immunosensors, a curve response (Figure 12) was obtained. This curve is based in the value of the Rs in the Step V of the functionalization.

In this case, the LOD is $3.657 \mu \mathrm{g} \mathrm{L}^{-1}$, once again far below the MRL required. Nevertheless, in addition to the MRL obtained, we consider this curve as an important result because it corroborates the conclusions exposed above: in the frequency domain, the impedance contribution of the antibodies is larger than the gold particles contribution. At low atrazine concentrations, the amount of $\mathrm{Ab}_{2}$ (labelled with gold particles) is larger than at high atrazine concentrations. Therefore, if the contribution of the gold particles is higher, the Rs value should be maximum at high atrazine concentrations where the amount of gold is minimum; nevertheless, the curve shows a minimum Rs value at high atrazine concentrations. 


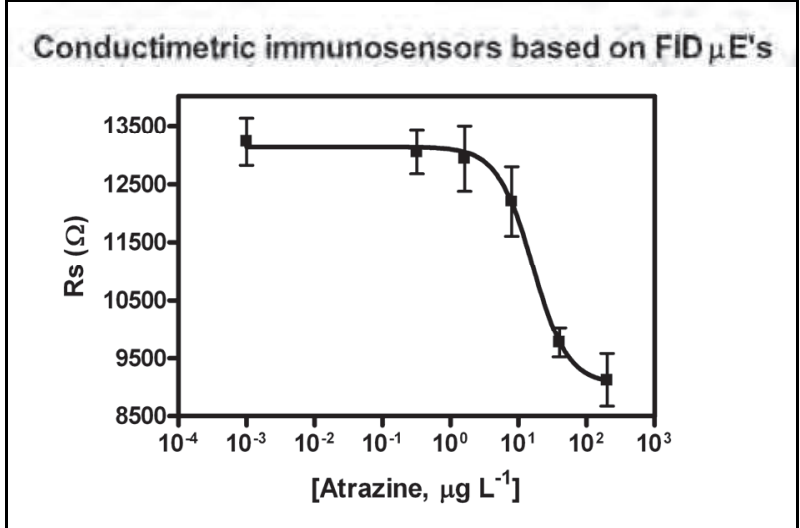

Fig. 12. Response curve of the conductimetric immunosensor, using the covalent immobilization technique, for the atrazine detection in relation with the Rs variation. Buffer solution was used for the competitive reaction. Measures were taken in diluted PBS solution. See Table 3 for the features of the atrazine assay.

Finally, the conductimetric response was also quantified. For that, the concentrations of atrazine $\left(0.32-2000 \mu \mathrm{g} \mathrm{L}^{-1}\right)$ were maintained. The electrodes were covered by a diluted PBS solution and the measurements were performed with a bias of $+100 \mathrm{mVdc}$. The response curve obtained can be seen in Figure 13. In this case, the curve is based on the current through the electrodes, related to amount of gold particles.

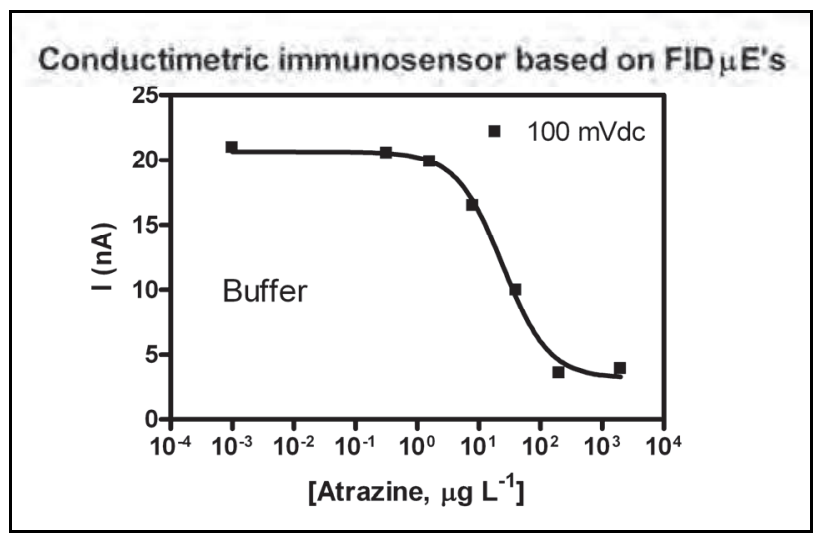

Fig. 13. Response curve of the conductimetric immunosensor, using the covalent immobilization technique, for the atrazine detection in relation with the presence of gold particles $(40 \mathrm{~nm})$. Buffer solution was used for the competitive reaction. Measures were taken in diluted PBS solution and the blank was reduced. See Table 3 for the features of the atrazine assay.

In this case, the LOD is $2.975 \mu \mathrm{L} \mathrm{L}^{-1}$ and the $\mathrm{R}^{2}$ was 0.9922 . Nevertheless, an additional conclusion is that in the conductimetric case, a very small gap is not needed to achieve the atrazine detection in low concentrations. 
The most relevant analytical features of the atrazine assays (impedimetric and conductimetric) are summarized in Table 3.

\begin{tabular}{lll}
\hline \multirow{2}{*}{$\begin{array}{l}\text { Features of the } \\
\text { atrazine assays }\end{array}$} & \multicolumn{2}{c}{ Conductimetric immunosensor (buffer) } \\
\cline { 2 - 3 } & impedimetric response & $\begin{array}{l}\text { conductimetric response } \\
(100 \mathrm{mV})\end{array}$ \\
\hline $\mathrm{IC}_{50} \mu \mathrm{g} \mathrm{L}^{-1}$ & $16.14 \pm 0.16$ & $24.17 \pm 0.03$ \\
$\mathrm{LOD}, \mu \mathrm{g} \mathrm{L}^{-1}$ & 3.657 & $\mathbf{2 . 9 7 5}$ \\
$\mathrm{R}^{2}$ & 0.89 & 0.99 \\
\hline
\end{tabular}

a The parameters are extracted from the four-parameter equation used to fit the standard curve.

Table 3. Features of the atrazine assays ${ }^{\mathrm{a}}$.

\section{Pesticide residues detection in red wine samples}

After the demonstration of both types of immunosensors for the detection of free pesticide in buffer samples, the immunosensors were studied using a complex matrix such as red wine samples. Red wine was chosen instead of other matrixes such as white wine, water or grape juice, because its strong matrix effect. Therefore, if the red wine matrix effect can be measured, the other matrix effects will be easier. Again, atrazine was used as pesticide of test.

\subsection{Analysis of Red Wine}

Red wine samples were obtained from a local retail store and used, on a first instance, to evaluate the extension of the potential non-specific interferences. Prior measurements with the immunosensors, the wine samples were purified by solid-phase extraction (SPE) using LiChrolut RP-18 (500 mg, 6 mL) sorbent (Merck, Darmstadt, Germany) pre-conditioned with $\mathrm{MeOH}(3 \mathrm{~mL})$, and MeOH:Mili-Q water $(15: 85, \mathrm{v} / \mathrm{v}, 3 \mathrm{~mL})$ at a flow rate of $3 \mathrm{~mL} \mathrm{~min}^{-1}$. The wine samples $(3 \mathrm{~mL})$ were loaded at $5 \mathrm{~mL} \mathrm{~min}^{-1}$, and the SPE cartridges washed with of MeOH:Mili-Q water (70:30, v/v, $1 \mathrm{~mL})$, dried, and finally eluted with of MeOH:Mili-Q water $(80: 20, \mathrm{v} / \mathrm{v}, 1 \mathrm{~mL})$. The fractions collected were diluted 1:50 in PBST and used for the impedimetric measurements [28].

\subsection{Impedimetric immunosensor}

\subsubsection{Detection method applied: Impedance spectroscopy}

As in section 4, impedance characterization measurements in a wide frequency range and fitting of the Nyquist plots of impedance spectra to an equivalent circuit, were applied as detection method.

Using the same conditions as in the measurements of the assay buffer and in order to qualitatively show how the impedimetric immunosensor is sensitive to the atrazine concentration using real samples, experiments were carried out including atrazine concentration between 0.32 to $2000 \mu \mathrm{g} \mathrm{L} \mathrm{L}^{-1}$ during the competition step (Step IV) using 
different ID's arrays for every concentration. Thus, the response curve shown in Figure 14 was obtained using the tool of detection based in a wide range of frequency, the covalent immobilization technique, as well as real samples (red wine) as medium for the competitive assay.

The limit of detection obtained from the response curve shown in Figure 14 was $\mathbf{0 . 1 9} \mu \mathbf{g} \mathbf{L}^{-\mathbf{1}}$. As in the previous case, this result is not only far below the MRL required by EC, but it also proves that atrazine can be detected with sub-ppb resolution when the competitive assay is performed in complex samples such as red wine.

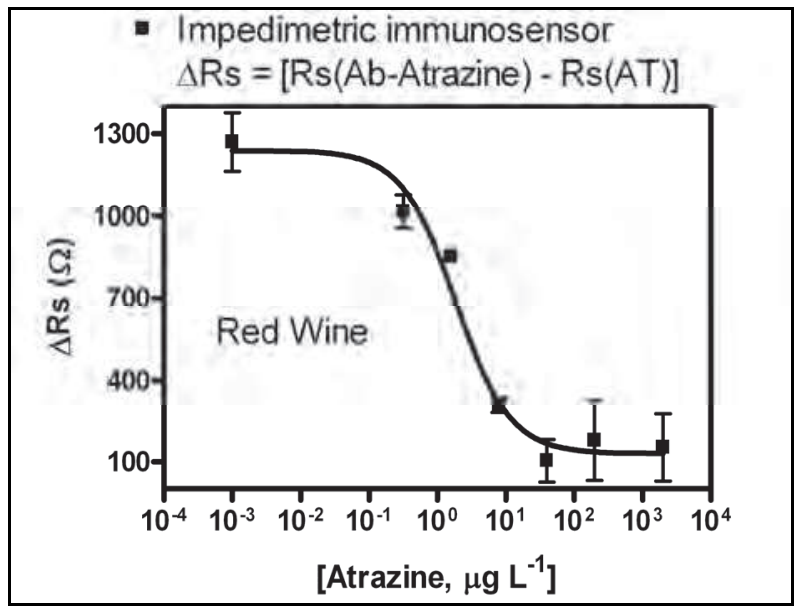

Fig. 14. Response curve of the impedimetric immunosensor, using the covalent immobilization technique, for atrazine detection in relation with the Rs variation. Real samples (red wine) were used for the competitive reaction. Measures were taken in diluted PBS solution. See Table 4 for the features of the atrazine assay.

\begin{tabular}{ll}
\hline $\begin{array}{l}\text { Features of the atrazine } \\
\text { assay }\end{array}$ & $\begin{array}{l}\text { Impedimetric immunosensor (Red } \\
\text { Wine) }\end{array}$ \\
\hline Signal $_{\text {min }}$ & $129.7 \mathrm{~b}$ \\
\hline Signal $_{\text {max }}$ & $1239 \mathrm{~b}$ \\
\hline Slope & -1.095 \\
\hline $\mathrm{IC}_{50, \mu \mathrm{L} \mathrm{L}^{-1}}$ & 1.876 \\
\hline $\mathrm{LOD}, \mu \mathrm{g} \mathrm{L}-1$ & $\mathbf{0 . 1 9}$ \\
\hline $\mathrm{R}^{2}$ & 0.86 \\
\hline
\end{tabular}

a The parameters are extracted from the four-parameter equation used to fit the standard curve.

${ }^{\mathrm{b}}$ Values presented are in $\Omega$.

Table 4 . Features of the atrazine assaysa. 


\subsection{Conductimetric immunosensor}

\subsubsection{Detection method applied: DC measuremnets}

As in the case of the impedimetric immunosensor, the conductimetric immunosensor assay was also done using red wine samples. In order to compare results, the same conditions used previously to analyze how the conductimetric immunosensor is sensitive to the atrazine concentration using real samples were maintained. Thus, the experiments carried out in this section included the same atrazine concentrations $\left(0.32-2000 \mu \mathrm{g} \mathrm{L}^{-1}\right)$ during the competition step (Step IV) using different ID's arrays for every concentration. Likewise, the electrodes were covered by a diluted PBS solution, and the measurements were performed to +25 and $+100 \mathrm{mVdc}$ bias.

The results obtained by this way are shown in Figure 15. Again, the blank was measured and reduced and the atrazine response continues to follow the inverse law which is a result of the competitive method of detection used. The limits of detection obtained for the detection of residues of atrazine, when the competitive assay was performed in red wine samples, were $\mathbf{0 . 4 8 9} \boldsymbol{\mu g ~ \mathrm { L } ^ { - 1 }}$ (100 $\mathrm{mVdc}$ bias) and $\mathbf{0 . 0 3 4} \boldsymbol{\mu g} \mathrm{L}^{-1}$ ( $25 \mathrm{mVdc}$ bias). Again, the MRL required by EC was largely reduced.

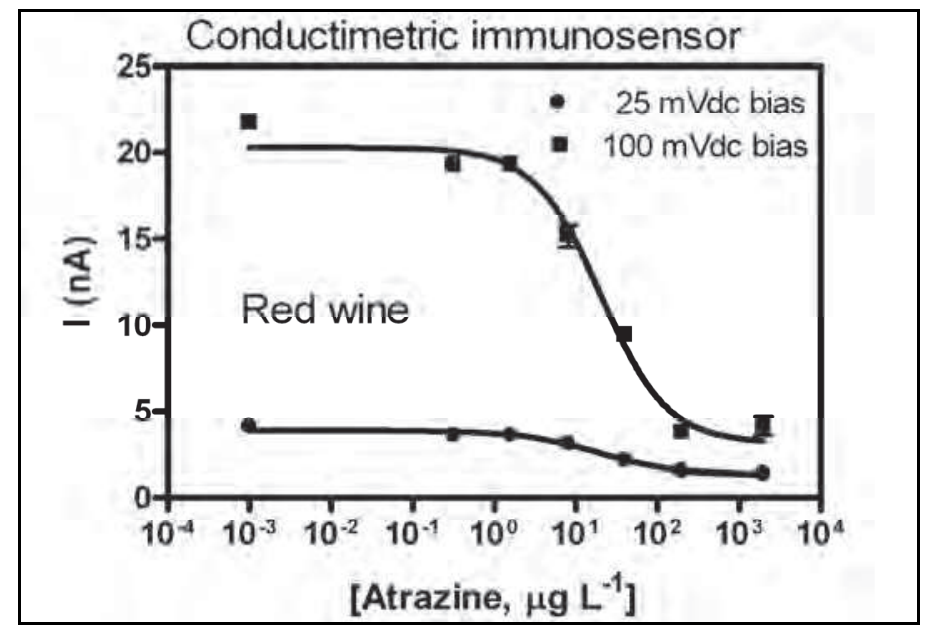

Fig. 15. Response curve of the conductimetric immunosensor, using the covalent immobilization technique, for atrazine detection in relation with the presence of gold particles $(40 \mathrm{~nm})$. Red wine samples were used for the competitive assay. Measures were taken in diluted PBS solution and the blank was reduced. See Table 5 for the features of the atrazine assay. 


\begin{tabular}{lll}
\hline \multirow{2}{*}{$\begin{array}{l}\text { Features of the } \\
\text { atrazine assays }\end{array}$} & \multicolumn{2}{l}{ Conductimetric immunosensor (red wine) } \\
\cline { 2 - 3 } & $25 \mathrm{mV}$ & $100 \mathrm{mV}$ \\
\hline $\mathrm{IC}_{50}, \mu \mathrm{g} \mathrm{L}^{-1}$ & $19.05 \pm 0.10$ & $20.54 \pm 0.07$ \\
$\mathrm{LOD}, \mu \mathrm{g} \mathrm{L}^{-1}$ & $\mathbf{0 . 0 3 4}$ & $\mathbf{0 . 4 8 9}$ \\
$\mathrm{R}^{2}$ & 0.96 & 0.98 \\
\hline
\end{tabular}

a The parameters are extracted from the four-parameter equation used to fit the standard curve.

Table 5. Features of the atrazine assays ${ }^{\mathrm{a}}$.

\section{Immunosensors comparison}

A comparison between the performance of the impedimetric and conductimetric immunosensors is shown in tables 6 and 7. From the data obtained is concluded that using either type of immunosensors, LODs far below the MRL can be obtained. These good results are directly related to the advantages of the immunosensors presented such as the use of ID $\mu E^{\prime} s$, the competitive assay based on the antibodies variation, as well as secondary antibody labelled with gold nanoparticles (in the case of the conductimetric immunosensor).

\begin{tabular}{lll}
\hline $\begin{array}{l}\text { Features of the } \\
\text { atrazine assays }\end{array}$ & $\begin{array}{l}\text { Impedimetric } \\
\text { immunosensor }\end{array}$ & $\begin{array}{l}\text { Conductimetric } \\
\text { immunosensor }\end{array}$ \\
\hline LOD, $\mu \mathrm{g} \mathrm{L}^{-1}$ & 0.04 & $0.104-1.217$ \\
\hline
\end{tabular}

a Limit of detection is extracted from the four-parameter equation used to fit the standard curve.

${ }^{b}$ Functionalization was performed by covalent immobilization techniques.

Table 6. Limit of detection of the atrazine assays performed in assay buffer a,b.

\begin{tabular}{lll}
\hline $\begin{array}{l}\text { Features of the } \\
\text { atrazine assays }\end{array}$ & $\begin{array}{l}\text { Impedimetric } \\
\text { immunosensor }\end{array}$ & $\begin{array}{l}\text { Conductimetric } \\
\text { immunosensor }\end{array}$ \\
\hline $\mathrm{LOD}, \mu \mathrm{g} \mathrm{L}-1$ & 0.19 & $0.034-0.489$ \\
\hline
\end{tabular}

a Limit of detection is extracted from the four-parameter equation used to fit the standard curve.

b Functionalization was performed by covalent immobilization techniques.

Table 7. Limit of detection of the atrazine assays performed in red wine samplesa,b 
In theory, a labelled biosensor must be more sensitive than a label-free biosensor; nevertheless, in our immunosensors this is not always the case. For this reason, we consider that the conductimetric immunosensor performance can still be improved (in order to reach the LODs obtained for the impedimetric immunosensor). To obtain this improvement, two main facts must be taken into account:

First, it is important to remark that the label used for the conductimetric immunosensor is not enzymatic, it is a conductive label. Thus, its influence is largely related to the aspect ratio between the particle diameter $(40 \mathrm{~nm})$ and the electrodes gap $(5000 \mathrm{~nm})$. In the conductimetric immunosensor presented here, this difference is large and, because of this, the neighbourhood of each particle becomes decisive. Therefore, in order to obtain a further improvement in the LOD this difference must be reduced, for example reducing the gap between electrodes.

Second, from the chemical point of view, one of the most important differences that exist between both immunosensors is that the conductimetric one includes a second antibody. Inevitably, the inclusion of the secondary antibody affects the immunosensor performance, because the antibody has a different electrical behaviour than the gold particle linked to it. Thus, another interesting approach related the conductimetric immunosensor would be to directly include the gold nanoparticle to the first antibody, therefore eliminating the second antibody.

\section{Conclusions}

In this chapter, two types of immunosensors for accurate and rapid pesticide residues detection in wine samples have been explained. These devices were designed in order to meet the need of legislation that establish the limits of pesticides in wine, as well as a system which improves the control of these residues by means of the application of innovative immunodiagnostic microarray devices for rapid at line assessment of pesticides in wine processing operations.

The immunosensors presented have been named: impedimetric immunosensors and conductimetric immunosensor. The impedimetric immunosensor is based on an array of interdigitated $\mu$-electrodes $(\mathrm{ID} \mu \mathrm{E})$ and bioreagents specifically developed (antigen, antibody) to detect residues of pesticide, uses unlabelled antibodies. The conductimetric immunosensor incorporates gold nanoparticles additionally. Bioreagents were covalently immobilized on the surface of the electrodes (interdigital space). In both cases the biochemical determination of pesticide is possible without any redox mediator.

For the case of the impedimetric immunosensor, the detection method is based on impedimetric measurements (in a wide range of frequencies and at single frequency), whereas in the case of the conductimetric immunosensor the detection method is based on conductimetric measurements (DC measurements).

The potential of the immunosensors to detect pesticides has been evaluated using atrazine in assay buffer as well as in red wine samples. Both immunosensors are different and each of them gives different advantages: 
i. The impedimetric immunosensor does not require the use of any label to achieve the detection of small amounts of atrazine;

ii. The impedimetric immunosensor has demonstrated the possibility of sub-ppb atrazine detection, even when the competitive assay is done in complex samples such as red wine.

iii. The conductimetric immunosensor offers the possibility of detecting small amounts (sub-ppb also) of atrazine by means of simple and inexpensive DC measurements. This opens the possibility of obtaining a commercial immunosensor of very easy use (it does not require qualified personnel), transportable and cost effective.

\section{References}

[1] Laureyn, W., et al., Nanoscaled interdigitated titanium electrodes for impedimetric biosensing. Sensors and Actuators B, 2000. 68: p. 360-370.

[2] Hleli, S., et al., Atrazine analysis using an impedimetric immunosensor based on mixed biotinylated self-assembled monolayer. Sensors and Actuators B, 2006. 113: p. 711717.

[3] Helali, S., et al., A disposable immunomagnetic electrochemical sensor based on functionalised magnetic beads on gold surface for the detection of atrazine. Electrochimica Acta, 2006. 51: p. 5182-5186.

[4] Valera, E., Á. Rodríguez, and L.M. Castañer, Steady-State and Transient Conductivity of Colloidal Solutions of Gold Nanobeads. Nanotechnology, IEEE Transactions on, 2007. 6(5): p. 504-508.

[5] Cosnier, S., Biomolecule immobilization on electrode surfaces by entrapment or attachment to electrochemically polymerized films. A review. Biosensors \& Bioelectronics, 1999. 14: p. 443-456.

[6] Kandimalla, V.B., V.S. Tripathi, and H. Ju, Immobilization of Biomolecules in Sol-Gels: Biological and Analytical Applications. Critical Reviews in Analytical Chemistry, 2006. 36(5): p. 73-106.

[7] Meyer-Plath, A.A., et al., Current trends in biomaterial surface functionalizationnitrogen-containing plasma assisted processes with enhanced selectivity. Vacuum, 2003. 71: p. 391-406.

[8] Siow, K.S., et al., Plasma Methods for the Generation of Chemically Reactive Surfaces for Biomolecule Immobilization and Cell Colonization - A Review. Plasma Processes and Polymers, 2006. 3: p. 392-418.

[9] Luzinov, I., et al., Epoxy-Terminated Self-Assembled Monolayers: Molecular Glues for Polymer Layers. Langmuir, 2000. 16: p. 504-516.

[10] Fredj, H.B., et al., Labeled magnetic nanoparticles assembly on polypyrrole film for biosensor applications. Talanta, 2008. 75(3): p. 740-747.

[11] Salmain, M., N. Fischer-Durand, and C.-M. Pradier, Infrared optical immunosensor: Application to the measurement of the herbicide atrazine. Analytical Biochemistry, 2008. 373: p. 61-70. 
[12] Helali, S., et al., Surface plasmon resonance and impedance spectroscopy on gold electrode for biosensor application. Materials Science and Engineering C, 2007. 28(5-6): p. 588-593.

[13] Zacco, E., et al., Electrochemical biosensing of pesticide residues based on affinity biocomposite platforms. Biosensors and Bioelectronics, 2007. 22: p. 17071715.

[14] Anh, T.M., et al., Detection of toxic compounds in real water samples using a conductometric tyrosinase biosensor. Materials Science and Engineering C, 2006. 26: p. 453-456.

[15] Steinheimer, T.R., HPLC Determination of Atrazine and Principal Degradates in Agricultural Soils and Associated Surface and Ground Water. J. Agric. Food Chem., 1993. 41: p. 588-595.

[16] Kaune, A., et al., Soil Adsorption Coefficients of s-Triazines Estimated with a New Gradient HPLC Method. J. Agric. Food Chem., 1998. 46: p. 335-343.

[17] Moore, A. and C.P. Waring, Mechanistic Effects of a Triazine Pesticide on Reproductive Endocrine Function in Mature Male Atlantic Salmon (Salmo salar L.) Parr. Pesticide Biochemistry and Physiology, 1998. 62: p. 41-50.

[18] Papiernik, S.K. and R.F. Spalding, Atrazine, Deethylatrazine, and Deisopropylatrazine Persistence Measured in Groundwater in Situ under Low-Oxygen Conditions. J. Agric. Food Chem., 1998. 46: p. 749-754.

[19] Hou, Y., et al., Immobilization of rhodopsin on a self-assembled multilayer and its specific detection by electrochemical impedance spectroscopy. Biosensors and Bioelectronics, 2006. 21: p. 1393-1402.

[20] Hleli, S., et al., An immunosensor for haemoglobin based on impedimetric properties of a new mixed self-assembled monolayer. Materials Science and Engineering C, 2006. 26: p. 322-327.

[21] Ionescu, R.E., et al., Impedimetric immunosensor for the specific label free detection of ciprofloxacin antibiotic. Biosensors and Bioelectronics, 2007. 23: p. 549555.

[22] Lee, J.A., et al., An electrochemical impedance biosensor with aptamer-modified pyrolyzed carbon electrode for label-free protein detection. Sensors and Actuators B, 2008. 129: p. 372-379.

[23] Kang, X., et al., Glucose biosensors based on platinum nanoparticles-deposited carbon nanotubes in sol-gel chitosan/silica hybrid. Talanta 74, 2008. 74: p. 879886.

[24] Maggio, E.T., Enzyme-Immunoassay. 2nd edition ed. 1981, Florida: CRC Press.

[25] Valera, E., et al., Conductimetric immunosensor for atrazine detection based on antibodies labelled with gold nanoparticles. Sensors and Actuators B, 2008. 134: p. 95-103.

[26] Valera, E., et al., Determination of atrazine residues in red wine samples. A conductimetric solution. Food Chemistry, 2010. 122: p. 888-894.

[27] Yuqing, M., G. Jianguo, and C. Jianrong, Ion sensitive field effect transducer-based biosensors. Biotechnology Advances, 2003. 21: p. 527-534. 
[28] Ramón-Azcón, J., et al., An impedimetric immunosensor based on interdigitated microelectrodes $(\mathrm{ID} \mu \mathrm{E})$ for the determination of atrazine residues in food samples. Biosensors \& Bioelectronics, 2008. 23: p. 1367-1373. 


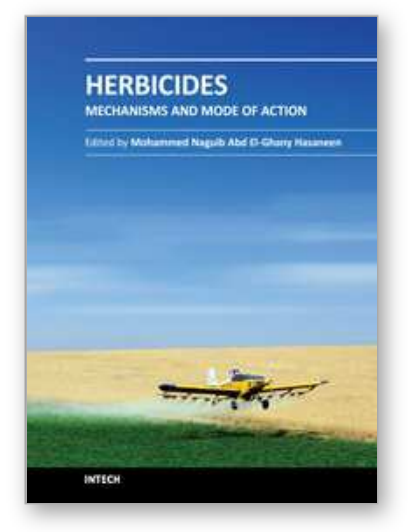

\author{
Herbicides - Mechanisms and Mode of Action \\ Edited by Dr. Mohammed Nagib Hasaneen
}

ISBN 978-953-307-744-4

Hard cover, 204 pages

Publisher InTech

Published online 22, December, 2011

Published in print edition December, 2011

This volume contains two sections: Mechanisms of herbicidal action (chapters 1-4) and Mode of action of selected herbicides on controlling diseased, weed growth and productivity and/or growth and development of field crops (chapters 5-10). Topics by chapters are: molecular mechanism of action, immunosensors , laboratory studies, molecular modeling, weed resistance, community response, use of herbicides in biotech culture, gene flow, herbicides and risk, herbicides persistence. These recurring themes reinforce my view, held over a very long time, that experience with one crop or problem can sometimes be relevant, often to an unexpected extent, to an apparently dissimilar situation in a different crop. I hope that readers interested in herbicides and pesticides will be satisfied with all the chapters in the book as its content might be of interest and value to them in the future.

\title{
How to reference
}

In order to correctly reference this scholarly work, feel free to copy and paste the following:

E. Valera and A Rodríguez (2011). Immunosensors Based on Interdigitated Electrodes for the Detection and Quantification of Pesticides in Food, Herbicides - Mechanisms and Mode of Action, Dr. Mohammed Nagib Hasaneen (Ed.), ISBN: 978-953-307-744-4, InTech, Available from:

http://www.intechopen.com/books/herbicides-mechanisms-and-mode-of-action/immunosensors-based-oninterdigitated-electrodes-for-the-detection-and-quantification-of-pesticides-

\section{INTECH}

open science | open minds

\author{
InTech Europe \\ University Campus STeP Ri \\ Slavka Krautzeka 83/A \\ 51000 Rijeka, Croatia \\ Phone: +385 (51) 770447 \\ Fax: +385 (51) 686166 \\ www.intechopen.com
}

\author{
InTech China \\ Unit 405, Office Block, Hotel Equatorial Shanghai \\ No.65, Yan An Road (West), Shanghai, 200040, China \\ 中国上海市延安西路65号上海国际贵都大饭店办公楼 405 单元 \\ Phone: +86-21-62489820 \\ Fax: +86-21-62489821
}


(C) 2011 The Author(s). Licensee IntechOpen. This is an open access article distributed under the terms of the Creative Commons Attribution 3.0 License, which permits unrestricted use, distribution, and reproduction in any medium, provided the original work is properly cited. 